\title{
Effect of laser treatment of unalloyed steel on the efficiency of benzotriazole as a corrosion inhibitor in a neutral medium
}

\author{
S.M. Reshetnikov, ${ }^{1,2}$ T.A. Pisareva, ${ }^{1 *}$ E.V. Kharanzhevsky, ${ }^{1}$ \\ F.Z. Gil'mutdinov' ${ }^{2}$ and E.M. Borisova ${ }^{1}$
}

${ }^{1}$ Federal State Budgetary Educational Institution of Higher Education "Udmurt State University”, Universitetskaya st., 1, bldg. 1, 426034 Izhevsk, Udmurt Republic, Russian Federation

${ }^{2}$ Federal State Budgetary Institution of Science "Udmurt Federal Research Center of the Ural Branch of the Russian Academy of Sciences”, Tatiana Baramzina st., 34, 426067 Izhevsk, Udmurt Republic, Russian Federation

*E-mail: tatianaapisareva@gmail.com

\begin{abstract}
The effect of laser irradiation on the corrosion-electrochemical behavior of samples made of low-carbon unalloyed steel in borate buffer solution at $\mathrm{pH} 7.4$ was studied. The modes of laser irradiation were determined (laser irradiation power $20 \mathrm{~W}$; pulse frequency $100 \mathrm{kHz}$; line width of the trajectory of the laser beam $50 \mathrm{~nm}$; scanning speed 350 (sample 2), 200 (sample 3), or 300 (sample 4) $\mathrm{mm} / \mathrm{s}$ ) ensuring the transition of steel to a passive state and a decrease in the overall rate of anodic dissolution of the metal. Laser irradiation of the samples was carried out in the air atmosphere. After laser treatment, some samples were studied in the same solution with addition of benzotriazole as a corrosion inhibitor. This inhibitor was chosen due to the fact that, like other azoles, it can be present in solution in the form of the initial molecules as well as in protonated form. It has been found that the nanoscale phases created by laser treatment decrease the surface oxidation rate under anodic polarization due to facilitation of transition to the passive state and thus favor an increase in the inhibitor efficiency. The results of XPS and microscopic studies show that laser surface treatment results in the formation of various types of adsorption centers. The assumption is substantiated that the adsorption centers after laser irradiation can be represented by various forms of iron oxides, including nonstoichometric, chemisorbed oxygen, as well as areas of nonoxidized (zero-valent) iron. Depending on the type of adsorption centers, benzotriazole molecules or possible protonation products can be adsorbed with formation of adsorption bonds of various nature.
\end{abstract}

Keywords: laser treatment, protective layers, corrosion, corrosion inhibitors, benzotriazole. Received: August 11, 2020. Published: September 18, 2020 doi: $\underline{10.17675 / 2305-6894-2020-9-3-21}$ 


\section{Introduction}

The ability of corrosion inhibitors to be adsorbed on the surface of a metal being protected is one of the factors that determine the inhibitor efficiency. Numerous experimental data (see, e.g., reviews [1-4]) indicate that, as a rule, the relationship between the efficiency of protection is symbiotic to the degree of the metal surface coverage with inhibitors. It is for this reason that the researchers who are developing new individual or mixed inhibitors strive to synthesize compounds capable of creating stable adsorption layers.

On the other hand, it is known that the adsorption of inhibitors on metals can be increased by various surface treatment methods: laser treatment, ion implantation, mechanical deformation of the surface, etc. [5-7]. The so-called high-power methods for treating the surface of metals, including laser irradiation [7], should be mentioned specially.

In particular, it was shown [7] that in some cases, laser treatment in pulsed mode creates highly efficient non equilibrium nanoscale layers on the surface, which can differ significantly in adsorption activity and corrosive properties from the original surface.

In view of the above, the purpose of this work was to study the effect of pulsed laser treatment of unalloyed steel on the efficiency of benzotriazole (BTA), an adsorption-type corrosion inhibitor.

\section{Materials and Experimental}

Low-carbon unalloyed sheet steel st-08 (as delivered) was selected as the metal material for laser treatment in various modes. Plates sized $10 \times 10 \times 2 \mathrm{~mm}$ were cut from the steel sheet. They were cleaned with fine sandpaper P-900 and degreased with ethanol. The current conductors for connection to a potentiostat were made as insulated wires that were soldered to the back (not working) sides of samples for electrochemical studies. The non-working side and edges of the samples were coated with an insulating varnish.

Some of the samples underwent laser treatment with an LDesigner F1 fiber-optic ytterbium pulsed laser. The radiation wavelength was $1.065 \mu \mathrm{m}$ and the rated power was $40 \mathrm{~W}$. The speed of the scanning laser beam in the treatment zone and the pulse frequency were varied. The samples were treated in the air.

Electrochemical corrosion studies were performed in potentiodynamic mode using an IPC-Pro L potentiostat. The potential sweep rate was $2 \mathrm{mV} / \mathrm{s}$. A borate buffer solution (BBS) with $\mathrm{pH} 7.4$ was used as the background electrolyte. Solutions were prepared from reagents of no worse than "chemically pure" grade and distilled water. The experiments were performed with natural aeration of solutions at a temperature of $20 \pm 2^{\circ} \mathrm{C}$. A three-electrode cell with divided cathode and anode spaces was used, with a saturated silver chloride reference electrode and a platinum auxiliary electrode. The potentials in the text and figures are given with respect to the silver chloride reference electrode.

After immersing the electrodes in the electrolyte solution, a cathodic potential of $E=-1000 \mathrm{mV}$ was set, then anodic polarization was started up to a potential of $E=1200 \mathrm{mV}$. This technique resulted in some cathodic training of the sample, which subsequently ensured 
that conditionally active (pre-passive) dissolution of the electrode was observed with good reproducibility.

The BTA inhibitor was added to the BBS as a concentrate. The experiments were carried out at BTA concentrations from 0.1 to $2 \mathrm{~g} / \mathrm{L}$.

Some laser-treated samples were examined by X-ray photoelectron spectroscopy (XPS). A SPECS electron spectrometer was used. The main attention was paid to the state of iron on the surface and in the depth of the surface layer. For this purpose, the surface was etched with argon ions with an energy of $0.9 \mathrm{keV}$ at a current density of $12 \mu \mathrm{A} / \mathrm{cm}^{2}$. The etching rate was $\sim 1 \mathrm{~nm}$ per minute. An Olympus GZ metallographic microscope was also used to characterize the samples.

\section{Results and Discussion}

Figure 1 shows the anodic polarization curves of laser-treated electrodes and the electrode in the initial state for comparison. One can see that the laser treatment modes used reduce the dissolution currents of steel, both in the pre-passive (conditionally active) region and in the passive region. It should be noted that, as shown in [6,7], laser surface treatment of unalloyed steel can either increase the corrosion resistance of the metal or reduce it. An increase in the corrosion resistance is most commonly attributed to the fact that laser treatment facilitates the transition of the metal to the passive state. On treatment in the air, nanoscale oxide layers are formed on the surface, owing to which the surface passes to the passive state more readily. At the same time, if laser treatment is carried out in relatively severe modes that promote the formation of relatively thick oxide layers (up to $1 \mu \mathrm{m}$ ), the initial passivation period is replaced by the violation of the continuity of thick oxide layers and an increase in the anodic current due to repassivation. The latter can be attributed to the defectiveness of the resulting macro layers. The laser setup used allowed us to vary the treatment modes in a wide range.

In view of the above, some optimal modes were chosen to study the effect of laser treatment. These modes made it possible to obtain oxide layers with different protection efficiency. The modes of the treatment pulses can be characterized by the following parameters: power of laser irradiation $20 \mathrm{~W}$; pulse frequency $100 \mathrm{kHz}$; width of the line of the laser beam trajectory $50 \mathrm{~nm}$; the scanning rate was 350 (sample 2), 200 (sample 3), or $300 \mathrm{~mm} / \mathrm{s}$ (sample 4). The sample in the original state, i.e., without laser treatment, will hereinafter be referred to as sample 1 . The same numbers will indicate the laser treatment modes.

As noted above, it follows from Figure 1 that the laser treatment modes used in this study promote the transition of samples to the passive state. In fact, in a relatively mild mode 2 that is characterized, other things being equal, by a high scanning rate, the maximum current in the region of conditionally active dissolution decreases from $98 \mu \mathrm{A} / \mathrm{cm}^{2}$ (sample 1) to $52 \mu \mathrm{A} / \mathrm{cm}^{2}$ (sample 2). A decrease in the current is also observed in the passive region. In the modes with a lower scanning rate where thicker and more continuous surface 
layers are formed, the samples no longer have a region of conditionally active dissolution but manifest anodic currents of $15-20 \mu \mathrm{A} / \mathrm{cm}^{2}$ that are characteristic of the passive state.

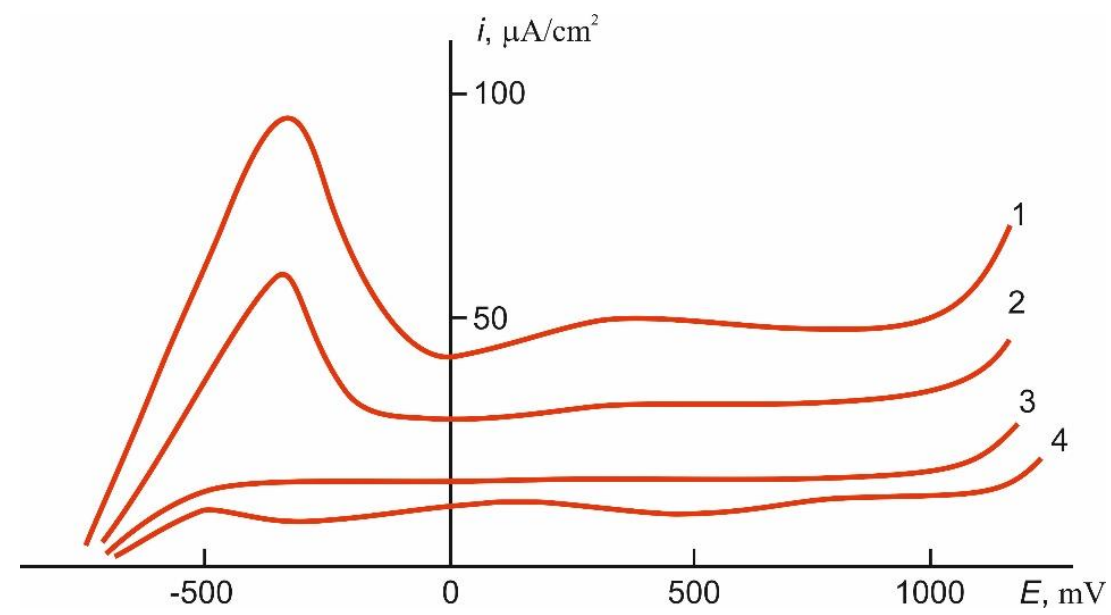

Figure 1. Anodic potentiodynamic curves for the polarization of steel st-08 in borate buffer solution at pH 7.4: 1 - sample 1 (without laser treatment); 2 - sample 2 (laser treatment in mode 2); 3 - the same in mode $3 ; 4$ - the same in mode 4.

Figure 2 shows the XPS spectra of the surface of sample 3 as an example. As noted above, the surface layer was etched with argon ions in order to study the distribution of the concentrations of elements over depth. The X-ray photoelectron spectra (XPS) of all the samples were obtained by excitation with $\mathrm{MgKa}$ irradiation $(1253.6 \mathrm{eV})$. The vacuum in the spectrometer chamber was $10^{-6} \mathrm{~Pa}$. The resolution (width at half maximum) on the Au $4 \mathrm{f} 7 / 2$ line was $1.2 \mathrm{eV}$. The relative error in determining the concentration of elements was $5 \%$ of the measured value (at medium concentrations). The accuracy of binding energy measurement was determined by the scanning step of $0.1 \mathrm{eV}$. It follows from Figure 2 that at a depth of $30 \mathrm{~nm}$, iron mainly exists in non-oxidized state.

Based on the data on the composition of the surface layer for sample 3 and for the other samples, the ratios of atomic concentrations $[\mathrm{Fe}] /[\mathrm{O}]$ in the laser-treated layer were calculated. To sum up these calculations, it can be believed that $\mathrm{Fe}(+2)$ and $\mathrm{Fe}(+3)$ stoichiometric oxides, non-stoichiometric oxides depleted in oxygen, as well as adsorbed (chemisorbed) oxygen are present on the surface at depths up to 10-20 nm.

As mentioned above, surface images of laser-treated samples were obtained using an Olympus GZ metallographic microscope. These images of samples treated in mode 3 are shown in Figure 3. One can see that the sample surface consists of regularly alternating dark bands (the surface layer where iron is predominantly oxidized) and light bands - depressions where iron is predominantly in zero-valent state. These stripes correspond to the trajectory of the laser beam during surface treatment. Note that in the XPS study, the signals that are obtained correspond to a certain averaged surface area that can contain nanoscale irregularities. For this reason, etching surface layers with argon ions during an XPS study provides information not only on the composition of deep layers but also on the composition of depressions corresponding to the given etching depth. In other words, in this particular 
case, zero-valent iron is formed both at the depth of the surface layer and in relief depressions. Thus, laser treatment creates two types of adsorption centers on the surface of samples, namely, areas of oxide forms of iron and areas of zero-valent iron. Taking into account the presence of chemisorbed oxygen, it may be assumed that the creation of various forms of adsorption centers on the surface of the samples can favor the adsorption of the BTA inhibitor.

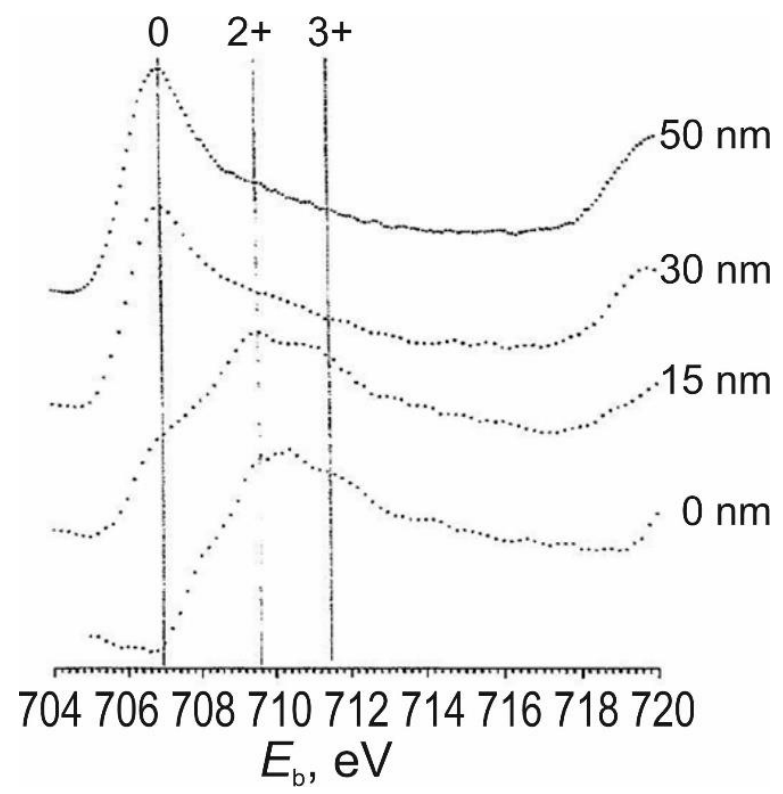

Figure 2. Fe2p $3 / 2 \mathrm{X}$-ray electron spectra of sample 3. Layer-by-layer etching with $0.9 \mathrm{keV}$ argon ions. The numbers at the vertical lines correspond to the oxidation state of iron and the depth of the analyzed layer.

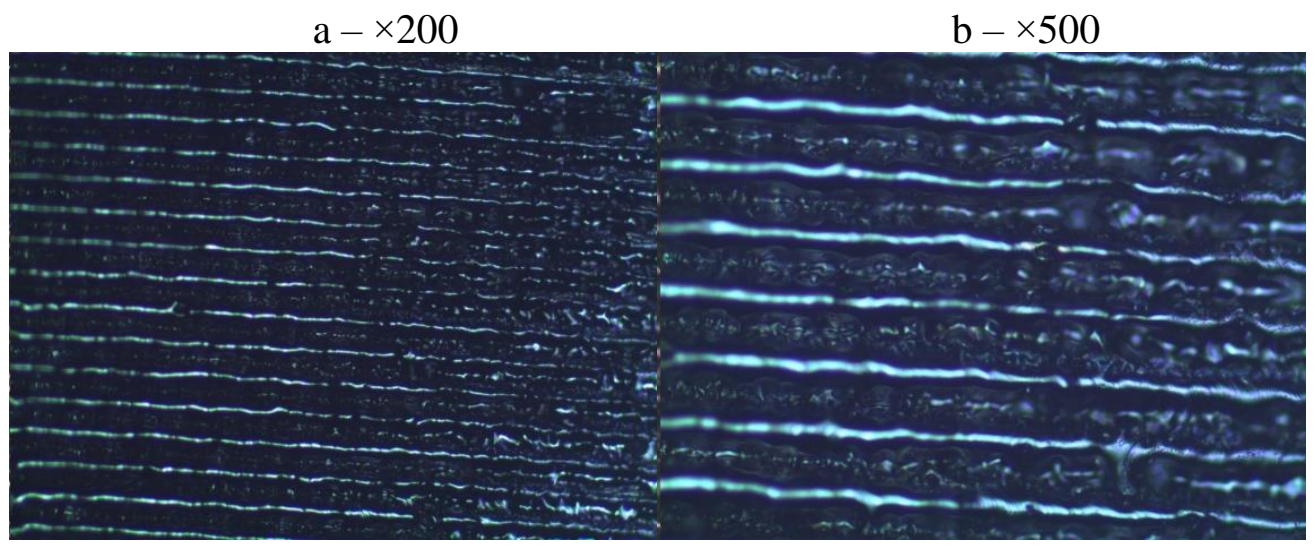

Figure 1. Electrode surface after laser treatment in mode 3.

Figure 4 shows the anodic potentiodynamic curves obtained during polarization of steel samples after laser treatment in the background solution and in a solution containing various BTA concentrations. Curves 1-4 were obtained during polarization of samples treated in mode 2 . One can see that the presence of BTA (curves 2-4) additionally favors a decrease in the rate of the anodic process both at potentials of conditionally active dissolution and 
passive dissolution. Comparison of data in Figures 3 and 4 shows that laser treatment increases the efficiency of BTA as a corrosion inhibitor. It should be noted that, according to [8], nano-sized surface elements have a higher surface energy, which enhances their adsorption properties.

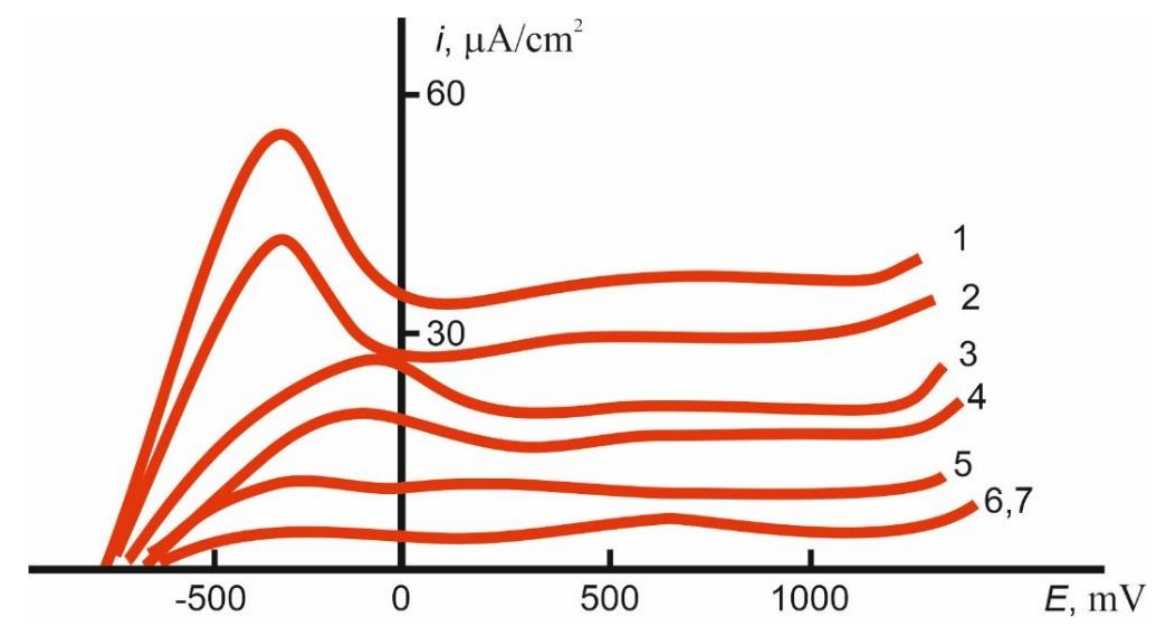

Figure 4. Anodic potentiodynamic curves during polarization of st-08 steel samples in borate buffer solution at $\mathrm{pH} 7.4$ after laser treatment with addition of the BTA inhibitor $(\mathrm{g} / \mathrm{l}): 1$ sample 2, without an inhibitor; 2 - sample 1, $1 \mathrm{~g} / \mathrm{l} \mathrm{BTA;} 3$ - sample 2, $0.1 \mathrm{~g} / \mathrm{l} ; 4$ - sample 2, $1 \mathrm{~g} / \mathrm{l} ; 5$ - sample 2, $2 \mathrm{~g} / \mathrm{l} ; 6,7$ - sample 3 , sample $4,1 \mathrm{~g} / \mathrm{l}$.

As noted above (Figure 1), samples treated in modes 3 and 4 show very low dissolution rates and no conditional active dissolution region, i.e., they are already in the passive state after laser treatment. However, addition of the inhibitor further decreases the anodic dissolution rate. Thus, one can see that preliminary laser treatment increases the efficiency of BTA inhibitor both in the active and passive dissolution regions.

Note that BTA and other azoles have long been known as corrosion inhibitors [9]. In recent years, studies carried out at A.N. Frumkin Institute of Physical Chemistry and Electrochemistry of the Russian Academy of Sciences elucidated the mechanisms of adsorption and inhibitory action of this class of compounds [3, 10-12]. First of all, it should be noted that BTA can undergo protonation in aqueous solutions to give a surface-active cation [13]. The degree of protonation increases with an increase in the medium acidity. However, cationic forms of BTA can be formed even in neutral media. Thus, both protonated BTA molecules and molecules in the initial, non-protonated state can act as inhibitors.

In this case, as assumed previously, the adsorption sites on steel surface after laser treatment will include oxides (hydroxides) of iron(+2) and iron $(+3)$, nonstoichiometric oxides, and chemisorbed oxygen. According to XPS, areas of non-oxidized iron also exist. In accordance with [10-12], the adsorption of BTA on a surface containing oxidized metal cations is accompanied by the formation of coordination surface compounds. In particular, this is confirmed by the chemical shift of the N1s spectrum of adsorbed BTA in comparison with the initial XP spectra of free BTA [10]. A peak corresponding to the binding energy of 
quaternized nitrogen after BTA protonation is clearly recorded in the XP spectra of BTA adsorbed on steel in acid media, which indicates the physical nature of adsorption $[11,12]$.

Moreover, one has to take into account the possibility of specific adsorption of BTA molecules on the sites containing zero-valent iron with participation of the lone electron pairs of nitrogen atoms.

Thus, it can be believed that laser treatment of unalloyed steel creates additional adsorption centers, thus enhancing the adsorption of BTA and increasing its protective efficiency.

\section{Conclusion}

Short-pulse laser treatment of unalloyed low-carbon steel (st-08) in the air results in the synthesis of nanosized surface structures in the form of stoichiometric and nonstoichiometric iron oxides as well as adsorbed oxygen. At the same time, as shown by XPS analysis, non-oxidized iron exists at depths more than 15-20 nm. As a result of laser treatment, the corrosion resistance of the test samples in borate buffer solution at $\mathrm{pH} 7.4$ increases.

The study of the corrosion-electrochemical behavior of steel samples in the initial state and after laser treatment with addition of BTA as a corrosion inhibitor to the borate solution showed that laser treatment enhances the protective effect of the inhibitor.

The assumption was made that as a result of laser treatment, the nature of the adsorption centers on the steel surface changes, which enhances the adsorption of BTA and increases its protective effect as a corrosion inhibitor.

\section{Acknowledgements}

The spectral and metallographic studies were performed using the equipment of the Center for Collective Use of the Udmurt Federal Research Center, Ural Branch of the Russian Academy of Sciences.

\section{References}

1. Yu.I. Kuznetsov, Sovremennoe sostoyanie teorii ingibirovaniya korrozii (The current state of corrosion inhibition theory), Zashch. Met. (Protection of Metals), 2002, 38, no. 2, 122-131 (in Russian).

2. Yu.I. Kuznetsov, Organic Inhibitions of Corrosion of Metals, N.-J.-L, Plenum Press, 1996, 283.

3. Yu.I. Kuznetsov and L.P. Kazansky, Physicochemical aspects of metal protection by azoles as corrosion inhibitors, Russ. Chem. Rev., 2008, 77, no. 3, 219-232.

4. S.M. Reshetnikov, Ingibitory kislotnoi korrozii metallov (Inhibitors if acid corrosion of metals), Leningrad, Khimiya, 1986, 144 (in Russian). 
5. O.V. Kasparova and Ya.M. Kolotyrkin, Vliyanie defektov kristallicheskoi reshetki na korrozionno-elektrokhimicheskoe povedenie metallov i splavov (Effect of crystal lattice defects on the corrosion-electrochemical behavior of metals and alloys), Itogi Nauki $i$ Tekh., Ser.: Korroz. Zashch. Korroz. (Advances in Science and Technology, Ser.: Corrosion and Corrosion Protection), Moscow, VINITI, 1981, 8, 51-101 (in Russian).

6. V.I. Kolotyrkin, V.M. Knyazheva and L.A. Yanov, Vysokoenergeticheskie sposoby obrabotki poverkhnosti dlya zashchity metallov ot korrozii (High-power surface treatment methods for corrosion protection of metals), Itogi Nauki i Tekh., Ser.: Korroz. Zashch. Korroz. (Advances in Science and Technology, Ser.: Corrosion and Corrosion Protection), Moscow, VINITI, 1986, 12, 185-259 (in Russian).

7. S.M. Reshetnikov, E.V. Kharanzhevskii and E.E. Sadiokov, Povyshenie korrozionnoi stoikosti metallicheskikh materialov pri lazernoi obrabotke (Enhancing the corrosion resistance of metal materials upon laser treatment), Izhevsk, "Udmurtskii universitet" Publishing House, 2016, 116 (in Russian).

8. I.P. Suzdalev, Nanotekhnologii: fiziko-khimiya nanoklasterov, nanostruktur $i$ nanomaterialov (Nanotechnologies: physicochemistry of nanoclusters, nanostructures and nanomaterials), Moscow, "Librokom" Book House, 2009, 592 (in Russian).

9. A.I. Altsybeeva and S.Z. Levin, Ingibitory korrozii metallov (Metal corrosion inhibitors), 1968, Leningrad, Khimiya, 262 (in Russian).

10. N.A. Gladkikh, M.A. Maleeva, L.B. Maksaeva, M.A. Petrunin, A.A. Rybkina, T.A. Yurasova, A.I. Marshakov and R.Kh. Zalavutdinov, Localized dissolution of carbon steel used for pipelines under constant cathodic polarization conditions. Initial stages of defect formation, Int. J. Corros. Scale Inhib., 2018, 7, no. 4, 683-696. doi: 10.17675/2305-6894-2018-7-4-14

11. Ya.G. Avdeev, D.S. Kuznetsov, M.V. Tyurina, A.Yu. Luchkin and M.A. Chekulaev, Protection of chromium-nickel steel in hydrochloric acid solution by a substituted triazole, Int. J. Corros. Scale Inhib., 2015, 4, no. 1, 1-14. doi: 10.17675/2305-68942015-4-1-001-014

12. Ya.G. Avdeev, D.S. Kuznetsov, M.V. Tyurina and M.A. Chekulaev, Protection of nickel-chromium steel in sulfuric acid solution by a substituted triazole, Int. J. Corros. Scale Inhib., 2015, 4, no. 2, 146-161. doi: 10.17675/2305-6894-2015-4-1-146-161

13. V.I. Ivanskii, Khimiya geterotsiklicheskikh soedinenii (Chemistry of heterocyclic compounds), Moscow, Vysshaya shkola, 1978, 236 (in Russian). 